\title{
CONCEPÇÕES DE APRENDIZAGEM EM ESTUDANTES UNIVERSITÁRIOS(AS) PORTUGUESES(AS)
}

\author{
António M. Duarte
}

\begin{abstract}
Resumo Este estudo procurou caracterizar as concepções de aprendizagem de estudantes universitários(as) portugueses(as). Uma amostra de estudantes respondeu a uma questão aberta sobre o significado, o processo e o contexto da aprendizagem. As respostas foram sujeitas a uma análise de conteúdo. Os resultados replicam a maioria das concepções de aprendizagem descritas pela investigação "fenomenográfica" (i.e. a distinção é entre aprendizagem enquanto memorização e enquanto compreensão). Surgiu também uma concepção da aprendizagem pouco registada, que define esta como conjugação da memória com a compreensão. Parecem também terem emergido novas variantes de algumas concepções de aprendizagem conhecidas (i.e. "aprende-se": praticando exploratoriamente; por compreensão da aprendizagem; através da motivação), assim como uma concepção aparentemente nova (i.e. a aprendizagem como compreensão e aplicação de conhecimento).
\end{abstract}

Palavras-chave Aprendizagem académica, concepções de aprendizagem, fenomenografia.

\section{Introdução}

O modo como os (as) estudantes abordam e alcançam sucesso nas tarefas académicas associa-se com a forma como representam o processo de aprendizagem.

A "fenomenografia" fundou-se como disciplina de investigação interessada em compreender as concepções "ingénuas", ou de "senso comum", sobre a aprendizagem (e.g. Marton \& Booth, 1997). De esta forma, procura clarificar as variações da representação sobre a aprendizagem, empregando uma metodologia qualitativa (i.e. entrevistas ou questionários abertos sobre o significado pessoal da aprendizagem, seguidos de análise de conteúdo das respostas).

Nesta perspectiva, a concepção de aprendizagem define-se como a representação que os indivíduos (e particularmente os/as estudantes) têm de este fenómeno. No entanto, tal não implica que aquela concepção seja considerada como uma "construção individual interna". Efectivamente, por estarmos imersos numa cultura, a nossa representação da aprendizagem é modelada socialmente, particularmente através de uma linguagem partilhada. Mas tal também não implica que essa representação seja veiculada linearmente do exterior porque, paralelamente, a concepção que temos da aprendizagem também influencia a representação social vigente (Marton \& Booth, 1997).

Considerando a investigação fenomenográfica sobre as diferentes 
representações que os/as estudantes têm sobre a aprendizagem, é possível concluir pela existência de duas concepções básicas (e.g. Säljö, 1984).

Em primeiro lugar, ressalta uma concepção "quantitativa", onde a aprendizagem, enquanto actividade estereotipada, é definida como recolha e acumulação (por memorização) de unidades discretas de informação, a reproduzir nas situações de avaliação ou a aplicar algoritmicamente. Esta parece constituir a concepção de aprendizagem para a qual tende a maior parte dos(as) estudantes (e.g., Davies, 1995).

Em contraste, emerge uma concepção "qualitativa", para a qual a aprendizagem, enquanto actividade estratégica, constitui um processo de compreensão e/ou construção de significados, através do relacionamento do conhecimento formal com a realidade e com a experiência, o que resulta no desenvolvimento pessoal.

Como se pode constatar, as duas concepções básicas discriminam-se, principalmente, pela noção de significado - ausente na representação "quantitativa" da aprendizagem. Diferenciam-se, igualmente, pelo grau de estruturação das asserções que as exprimem. A concepção "quantitativa" de aprendizagem tende a ser expressa de modo menos elaborado e organizado, qualificando incipientemente a aprendizagem, como se esta fosse óbvia. Por outro lado, a concepção "qualitativa" tende a exprimir-se de forma bastante elaborada e integrada (e.g. Boulton-Lewis, Wilss, \& Mutch, 1994).

As duas concepções de aprendizagem podem assim ser conceptualizadas hierarquicamente - considerando-se a concepção "qualitativa" como englobando a "quantitativa". Efectivamente, enquanto que esta facilmente dá conta da aprendizagem de conteúdos simples (por ex. factos e competências básicas), já não é suficiente no que toca à aprendizagem de conteúdos de nível superior, para a qual se exige uma representação patente na concepção "qualitativa". ${ }^{1}$

Complementando as duas concepções de aprendizagem apresentadas, Biggs e Moore (1993) sugerem a existência de uma concepção dita "institucional", que representa a aprendizagem enquanto obtenção do reconhecimento, pela escola, de que foram atingidos os "padrões" aceites (comprovados pelas classificações). De acordo com esta terceira concepção básica, a evidência de aprendizagem é atestada pelo sucesso escolar e a evidência de uma "boa aprendizagem" pelas boas classificações (Biggs, 1990).

Os estudos realizados permitem concluir que, paralelamente à concepção "institucional", as concepções "quantitativa" e "qualitativa" diferenciam-se em concepções mais específicas. O sistema de descrição de concepções específicas de aprendizagem apresentado por Marton, Dall'Alba e Beaty (1993) parece apresentar-se como estável em diferentes contextos, tendo sido corroborado por outros investigadores (e.g. Cliff, 1998). De acordo com este sistema, existem seis concepções

1 A hierarquização das concepções de aprendizagem é coerente com o facto de existir uma evolução da concepção "quantitativa" para a concepção "qualitativa" com o desenvolvimento pessoal (e.g. Säljö, 1979), o que aliás joga com a noção "fenomenográfica" de que a evolução da concepção de um fenómeno equivale à consciencialização de mais ou novos aspectos desse fenómeno (Marton \& Booth, 1997). 
específicas de aprendizagem: as três primeiras são instâncias da concepção "quantitativa" e as três últimas da concepção "qualitativa".

A primeira concepção define a aprendizagem como aumento de conhecimento, caracterizando-se pelo emprego de definições vagas, que se limitam a recorrer a sinónimos da palavra aprendizagem. O processo de aprendizagem é tido aqui como mera aquisição e armazenamento de informação, por acrescento à existente, tendo lugar no contexto da vida pessoal.

Asegunda concepção apresenta a aprendizagem como memorização e reprodução. A aprendizagem é aqui conseguida através da memorização por repetição, situando-se, exclusivamente, no contexto educacional.

A terceira concepção de aprendizagem toma esta como memorização e aplicação. Neste caso, o processo de aprendizagem consiste em recuperar e utilizar informação armazenada, que pode ser adaptada às circunstâncias do contexto de vida pessoal.

A quarta concepção, da aprendizagem como compreensão, define-a como compreensão de significado. De acordo com esta concepção existem várias formas de esta compreensão se processar: por exame crítico da matéria; por análise da relação entre as partes da matéria e de esta com outras informações; por desenvolvimento de uma perspectiva nova; e por consciência de diferentes perspectivas sobre a matéria. Também neste caso o palco da aprendizagem tende a ser definido como o contexto do estudo académico.

Aquinta concepção de aprendizagem refere-se a esta como reinterpretação, entendida como mudança da concepção que se tem das coisas e, eventualmente, como conhecimento de diferentes perspectivas sobre elas. Esta reinterpretação pode processar-se de duas formas: por aumento do conhecimento ou por generalização do que se aprende num domínio a outros domínios. O contexto da aprendizagem é aqui alargado, ultrapassando as fronteiras da escola e do estudo.

Finalmente, para a sexta concepção - a da aprendizagem como mudança pessoal - , que acrescenta o aspecto existencial da aprendizagem, a reinterpretação de conhecimento conduz a (ou representa) uma mudança pessoal. O processo de aprendizagem é tido como: o estabelecimento de uma "reciprocidade" entre sujeito e objecto; uma mudança pessoal contínua; ou uma compreensão de como se efectua o próprio processo de compreensão, o que envolve uma percepção de si próprio como mais capaz (i.e. em controlo). Neste caso, o contexto de aprendizagem é tido como o mais alargado possível, uma vez que aquela é vista fora dos limites da experiência pessoal e do próprio tempo.

No quadro 1 é apresentado um resumo de este sistema de seis concepções de aprendizagem.

Note-se que de este sistema ressalta a existência de diferentes dimensões da concepção de aprendizagem: a) uma dimensão referencial, que diz respeito à noção daquilo que é aprendido (por ex. "aumento de conhecimentos" ou "nova perspectiva"); b) uma dimensão processual, que se refere ao modo como a aprendizagem se realiza (por ex. "enchendo" ou "compreendendo"); c) uma dimensão contextual, que se refere ao contexto onde a aprendizagem se realiza (a "escola" ou "o mundo"). 
Quadro 1 O sistema de concepções de aprendizagem de Marton, Dall'Alba e Beaty (1993)

\begin{tabular}{lll}
\hline O que é aprender & Como se aprende & Onde se aprende \\
\hline 1. Aumento de conhecimento & Aquisição e armazenamento de informação & Contexto da vida pessoal \\
2. Memorização de informação & Repetição e reprodução de informação & Contexto educacional \\
$\begin{array}{l}\text { 3. Memorização e aplicação de } \\
\text { informação }\end{array}$ & Recuperação e utilização da informação & Contexto da vida pessoal \\
4. Compreensão & $\begin{array}{l}\text { Exame crítico, análise de relações, ou } \\
\text { consciência/desenvolvimento de perspectivas }\end{array}$ & Contexto académico \\
5. Reinterpretação & Aumento de conhecimento ou generalização & Contexto amplo \\
6. Mudança pessoal & "Reciprocidade" sujeito-objecto ou & Contexto amplo \\
\hline
\end{tabular}

Estudos mais recentes recolheram também indícios da possível existência de novas concepções de aprendizagem: uma concepção "intermédia" e uma concepção "comunitária".

A concepção a que chamamos "intermédia" (registada primeiro em estudantes asiáticos(as)) parece situar-se na fronteira entre a concepção "quantitativa" e a "qualitativa", representando a aprendizagem quer como memorização de significado (i.e. retenção do que é compreendido), quer como compreensão através da memorização (Marton \& Booth, 1997). ${ }^{2}$ Outras investigações (com estudantes ocidentais), revelam igualmente a possibilidade de se conceber a aprendizagem como resultado da conjugação entre a memorização, responsável pela acumulação de conhecimento, e a compreensão, que possibilita uma mudança de perspectiva (e.g. Cliff, 1998).

Por sua vez, a concepção "comunitária" (também mais típica em estudantes não ocidentais) equivale a uma representação normativa da aprendizagem enquanto obrigação social (e.g. Cliff, 1998). Esta concepção define a aprendizagem como uma obrigação moral para com: a) o/a próprio(a) (i.e. discriminar o que é positivo e negativo para si); b) as figuras de autoridade (o/a professor(a), Deus); ou c) a comunidade de referência. Atenda-se, no entanto, que esta representação da aprendizagem pode associar-se tanto à concepção "quantitativa" como à "qualitativa", sugerindo, no nosso entender, que pode não tanto ser uma concepção distinta como uma outra dimensão das duas concepções estabelecidas (i.e. a função da aprendizagem). De qualquer forma, os resultados de estes estudos apresentam diferenças interessantes em relação aos estudos com estudantes ocidentais, para os/as quais a aprendizagem constitui fundamentalmente um processo centrado no indivíduo.

2 Talvez esta concepção de aprendizagem ocorra no Oriente devido à transferência, para o contexto académico, da prática cultural de memorização de tradições sagradas, tidas como informação significativa (Dahlin \& Regmi, 1997). 
Como é que as concepções de aprendizagem se exprimem no que toca a tarefas específicas de aprendizagem? Embora escassos, alguns estudos permitiram compreender como os/as estudantes concebem a aprendizagem nas tarefas de leitura, escrita, e aprendizagem com computador.

No que toca à leitura, regista-se a diferenciação entre uma concepção "quantitativa", expressa na ideia daquela como imposição exterior, e do(a) leitor(a) como agente passivo, de uma concepção "qualitativa", que defende a leitura como o confronto entre a perspectiva do autor e do(a) leitor(a) (e.g. Säljö, 1984).

No que diz respeito à composição escrita, foram também identificadas duas concepções básicas (Hounsell, 1988). Numa concepção "quantitativa", a escrita é tida basicamente como um "instrumento" para corresponder a exigências externas, constituindo uma recolha e reprodução, não selectiva, de informação. A estruturação do texto é representada aqui como mera ordenação de unidades discretas, do qual é ausente um ponto de vista explícito. Em contraponto, de acordo com uma concepção "qualitativa" da escrita, esta é representada como uma forma de aprendizagem e de expressão pessoal, envolvendo a estruturação integrada de um argumento pessoal.

Foram também detectados indícios (van den Brink et al., 2000) de que os/as estudantes podem representar a tarefa de aprendizagem com o computador em termos: a) "quantitativos" (i.e. o computador como meio de aquisição de informação a aplicar) b) "qualitativos" (i.e. o computador como facilitador da compreensão sobre as matérias); c) "institucionais" (i.e. o computador como meio de obter classificações). O computador parece ser representado como um recurso que pode aumentar a eficiência de qualquer tipo de aprendizagem, pelo facto de, na ideia dos(as) estudantes, "aumentar a motivação", "acelerar a aprendizagem" ou "reduzir a carga de informação".

A concepção de aprendizagem de um(a) estudante pode ter uma influência significativa no seu processo e no seu resultado de aprendizagem.

Efectivamente, a concepção "quantitativa" de aprendizagem pode associar-se, por vezes, a uma abordagem "superficial" da aprendizagem (Van Rossum. \& Schenck, 1984). ${ }^{3}$ No entanto, alguns estudos parece revelar que esta concepção não conduz necessariamente a este tipo de abordagem (e.g. Rosário, 1999).

Em contraste, uma concepção "qualitativa" de aprendizagem pode associar-se, por vezes, a uma maior persistência nas tarefas (Lamon et al., 1993) e a uma abordagem "profunda" da aprendizagem (Van Rossum \& Schenk, 1984). ${ }^{4}$ No entanto, alguns estudos não conseguiram detectar esta congruência (e.g. Duarte, 2000), sugerindo que a concepção "qualitativa" não é condição suficiente para uma abordagem "profunda" da aprendizagem. Foi também argumentado que os/as

3 Aabordagem "superficial" da aprendizagem conjuga uma motivação "intrumental" (i.e. fazer o mínimo necessário para evitar o insucesso) com uma estratégia "superficial" (i.e. memorização passiva), tendendo a conduzir a um resultado de aprendizagem mais pobre.

4 A abordagem "profunda" da aprendizagem conjuga uma motivação intrínseca com uma estratégia "profunda" (i.e. baseada na compreensão), conduzindo, geralmente, a melhores resultados. 
estudantes com uma concepção "qualitativa" estariam em condição de poder optar, em função da tarefa, por uma abordagem "profunda" ou "superficial" à aprendizagem (Brown, 1994). De qualquer modo, a concepção "qualitativa" parece associar-se a classificações escolares mais elevadas e a uma melhor compreensão das matérias lidas (Lamon et al., 1993).

Que factores poderão explicar a detenção de diferentes concepções de aprendizagem?

Atendendo à relação, atrás exposta, entre concepção de aprendizagem e abordagem da aprendizagem, é pertinente pensar que esta pode também operar como factor daquela. O uso habitual de uma abordagem "superficial" da aprendizagem, por exemplo, pode condicionar uma concepção "quantitativa" de aprendizagem. Refira-se também que a promoção da consciência sobre as abordagens da aprendizagem utilizadas pode resultar no desenvolvimento da concepção de aprendizagem (e.g. Martin \& Ramsden, 1987). Paralelamente, as concepções de aprendizagem dos estudantes associam-se, de perto, com as suas concepções sobre o conhecimento (i.e. a sua "epistemologia pessoal") (Perry, 1970). Efectivamente, a concepção "quantitativa" parece estar directamente relacionada com uma epistemologia pessoal dualista (i.e. o conhecimento enquanto conjunto de verdades absolutas). Em contraste, a concepção "qualitativa" associa-se a uma epistemologia pessoal relativista (i.e. o conhecimento como algo construído) (e.g., Ryan, 1984).

Mas talvez a influencia mais significativa sobre a concepção de aprendizagem venha do ambiente em que a aprendizagem se realiza. Efectivamente, uma concepção "quantitativa" pode resultar de ambientes onde: os professores(as) têm uma concepção do mesmo tipo; os conteúdos são apresentados como unidades de informação a memorizar e reproduzir; os currículos e os sistemas de avaliação são muito rígidos; e existe uma elevada frequência de tarefas, que retira a oportunidade de reflexão (e.g. Hounsell, 1984). Paralelamente, uma concepção "qualitativa" pode resultar de contextos que desenvolvem o espírito crítico, através da exposição a diferentes perspectivas de conhecimento (Marton, Dall'Alba \& Beaty, 1993).

Neste artigo são apresentados o desenvolvimento e os resultados de um procedimento de avaliação qualitativa da concepção de aprendizagem de estudantes universitários(as). Pretendia-se, especificamente, testar a possível existência, no contexto português, dos diferentes tipos de concepção de aprendizagem propostos pela perspectiva "fenomenográfica", assim como detectar concepções eventualmente novas. ${ }^{5}$ 


\section{Método}

\section{Amostra}

A amostra de participantes foi extraída da população dos(as) estudantes universitários(as) que frequentavam os quatro primeiros anos de um curso superior de geografia de uma universidade em Lisboa. A amostra, de 252 estudantes, reflecte a população no que diz respeito à distribuição da variável sexo: comporta $136(54 \%)$ mulheres e $116(46 \%)$ homens. A distribuição das variáveis variante de estudo, ano de escolaridade, idade e média escolar pela variável sexo é relativamente equitativa. A idade dos(as) estudantes varia entre os 18 e os 49 anos, com uma média de 24,2 e um desvio padrão de 6,3 , apresentando a maioria $(73,8 \%)$ idades compreendidas entre os 18 e os 25 anos. No quadro 2 é possível analisar a distribuição dos estudantes da amostra global e de ambos os sexos por categorias de idade.

Quadro 2 Amostra

\begin{tabular}{cccc}
\hline Idade & Amostra global & Sexo feminino & Sexo masculino \\
\hline $18-21$ & $114(45,2 \%)$ & $68(50 \%)$ & $46(39,7 \%)$ \\
$22-25$ & $72(28,6 \%)$ & $42(30,9 \%)$ & $30(25,9 \%)$ \\
$26-29$ & $20(8 \%)$ & $8(5,9 \%)$ & $12(10,3 \%)$ \\
$30-33$ & $23(9,2 \%)$ & $8(5,9 \%)$ & $16(13,8 \%)$ \\
$34-37$ & $6(2,4 \%)$ & $4(2,9 \%)$ & $2(1,7 \%)$ \\
$38-41$ & $11(4,3 \%)$ & $3(2,2 \%)$ & $8(6,9 \%)$ \\
$43-49$ & $6(2,4 \%)$ & $4(2,9 \%)$ & $2(1,7 \%)$ \\
Total & $252(100 \%)$ & $137(100 \%)$ & $116(100 \%)$ \\
\hline
\end{tabular}

\section{Procedimento}

Com vista à caracterização da concepção de aprendizagem dos(as) participantes, foi-lhes colocada a questão aberta "O que é para si aprender?", à qual responderam por escrito. Os/as participantes foram instruídos(as) para relerem, no final, as suas respostas, para assegurar que elas eram suficientemente explícitas quanto a três aspectos: "o que é aprender", "como se aprende" e "onde se aprende" (correspondentes à dimensão "referencial", "processual" e "contextual" da concepção de aprendizagem). Para além disso, eram informados(as) de que não deviam centrar-se na forma particular como aprendem, mas sim na aprendizagem em geral. Salientava-se também a inexistência de respostas certas ou erradas, o anonimato, a confidencialidade e a voluntariedade.

A análise das respostas consistiu numa análise de conteúdo, que envolveu três momentos principais: 1) opção por um critério de segmentação das unidades a categorizar; 2 ) desenvolvimento de um sistema de categorias de 
análise; 3 ) testagem da confiança das categorias detectadas, por comparação entre juízes.

O critério utilizado para a segmentação das unidades a categorizar foi o de "segmentação por unidades temáticas" (Flores, 1994). Ou seja, todo o segmento de resposta que abordasse, pelo seu conteúdo, qualquer das dimensões focadas do fenómeno da aprendizagem (i.e. referencial $(\mathrm{R})$, processual $(\mathrm{P})$ ou contextual $(\mathrm{C})$ ), era considerado como uma unidade a categorizar, por correspondência com uma das categorias da respectiva dimensão (do sistema em desenvolvimento). ${ }^{6}$ Considerando a crítica ao método "fenomenográfico", de que este aliena os participantes dos seus depoimentos, ao isolar e retirar frases soltas do contexto em que estas foram produzidas (Säljö, 1984), a categorização procurou ser sensível à totalidade de cada resposta, de acordo com a sugestão de Svensson (1989, cit. por Eklund-Myrskog, 1998). Não foram consideradas respostas em que os indivíduos se referiam ao seu modo próprio de aprendizagem.

Para o desenvolvimento de um sistema de categorias de análise utilizou-se uma aproximação intermédia entre as ditas abordagens "indutiva" e "dedutiva" (Miles \& Huberman, 1994). Ou seja, partiu-se de um modelo teórico (i.e. o"fenomenográfico") para analisar os dados, "filtrando-os", sempre que possível, com base em categorias de análise pré-existentes. Simultaneamente, tentou-se manter a sensibilidade a aspectos não previstos, reformulando-se o modelo de partida com base em categorias emergentes. Assim, com base no sistema de seis concepções de aprendizagem descrito por Marton, Dall'Alba e Beaty (1993), procedeu-se a uma primeira análise das respostas, com o objectivo de verificar quais as categorias que eram confirmadas pelo contexto específico de este estudo, quais as categorias infirmadas e quais as categorias emergentes. Com base nos resultados de esta primeira análise, foi possível chegar a um segundo sistema de categorias de descrição das concepções de aprendizagem, que foi depois utilizado numa segunda análise das respostas por dois juízes. Numa "fase de formação dos juízes" estes procederam à leitura e discussão interpretativa do segundo sistema de categorias. Seguidamente, cada juiz procedeu à categorização, independentemente, de cerca de $10 \%$ das respostas, e foi efectuado um primeiro cálculo do acordo entre juízes. ${ }^{7}$ Foi depois estudado, com base em tabelas de contingência, o padrão de acordo/desacordo entre os dois juízes (i.e. as respostas em que, tendo um juiz categorizado de uma maneira, o outro categorizou da mesma ou de uma maneira diferente). Atendendo à deteç̧ão, por um dos juízes, de categorias não previstas no segundo sistema de categorização, foi posteriormente construído um terceiro e último sistema, com base no qual cada juiz procedeu à categorização independente de todas as respostas.

6 Neste caso, podemos portanto dizer que a segmentação das unidades coincide com a sua categorização ou, optando pela linguagem usada por Miles e Huberman (1994), que cada um dos três "códigos descritivos" ( $\mathrm{R}, \mathrm{Pe}$ ) foi categorizado com base num conjunto específico de "códigos interpretativos".

7 Para todos os cálculos de coeficiente de acordo foi utilizada a fórmula sugerida por Bakeman e Gottman (1986): $\mathrm{PA}=(\mathrm{Na} /(\mathrm{Na}+\mathrm{Nd}))$ 100; onde: "PA" é a percentagem de acordo; "Na" é a frequência dos acordos; " $\mathrm{Nd}$ " é a frequência dos desacordos. 
Quadro 3 Acordo interjulzes quanto às categorias de cada dimensão

\begin{tabular}{lccc}
\hline & Dimensão R & Dimensão P & Dimensão C \\
\hline Coeficiente de acordo & $81,9 \%$ & $86,5 \%$ & $95,2 \%$ \\
\hline
\end{tabular}

Para a categorização final de cada resposta, sempre que estava presente mais que uma categoria para a mesma dimensão, considerou-se a categoria mais elevada. Por exemplo: uma resposta onde estava presente a categoria R1 e a R3 era categorizada como R3 (com base na hierarquização sugerida no sistema de análise e que resultou do acordo integral dos dois juízes). ${ }^{8}$ De seguida, procedeu-se aos cálculos finais de acordo. Para efeitos de classificação final das respostas, a resolução dos desacordos foi efectuada por discussão conducente a uma categorização consensual. Cada juiz procedeu ainda à verificação da correcção da sua categorização, tal como sugerido por Garcia (1996), e foi calculado um índice da "consistência intrajuiz" para cerca de $10 \%$ das respostas categorizadas. No quadro 3 discrimina-se $o$ acordo interjuízes em cada dimensão. Como se pode observar, a magnitude de acordo entre juízes foi, para todas as dimensões, superior ou igual a $81,9 \%$. A magnitude de acordo intrajuiz foi superior ou igual a $65 \% .^{9}$

\section{Resultados}

A primeira análise (aplicação do primeiro sistema de categorias - baseado na teoria) permitiu confirmar a presença, neste contexto, das seis concepções específicas de aprendizagem descritas por Marton, Dall'Alba e Beaty (1993). Ou seja, também aqui aprender é tido como: 1) aumento de conhecimento; 2) memorização e reprodução; 3) memorização e aplicação; 4) compreensão; 5) reinterpretação; 6) mudança pessoal.

Registou-se igualmente a presença de uma concepção de aprendizagem enquanto conjugação entre a memorização e a compreensão da informação, análoga à concepção "intermédia" referida por Marton e Booth (1997) ou Cliff (1998). Note-se que não se registou a presença da concepção "institucional", referida por Biggs e Moore (1993) (i.e. aprender é obter classificações) ou da concepção "comunitária" (i.e. a aprendizagem enquanto obrigação social) identificada por Cliff (1998).

No que toca à dimensão referencial da concepção de aprendizagem (i.e. o que é aprender) é de referir a emergência de um tipo de respostas não previsto, e que sugere a necessidade de propor uma concepção nova. Chamaremos a esta "

8 A progressão no sistema de categorização exprime um aumento gradual da complexidade da concepção de aprendizagem.

9 A menor magnitude do acordo intrajuíz, relativamente ao acordo entre juízes, pode talvez ser explicada pelo facto de se ter utilizado, para aquele cálculo, apenas $10 \%$ das respostas categorizadas. 
compreensão e aplicação", por implicar uma definição da aprendizagem como um processo de compreensão do conhecimento associado à sua aplicação no mundo real.

Por seu lado, ao nível da dimensão processual (i.e. como se aprende), destaque-se que para o caso da sexta concepção específica (i.e. aprendizagem como mudança pessoal) não foram detectadas respostas que coincidissem com as noções documentadas de que se aprende por sucessivas mudanças pessoais, ou pela percepção do(a) próprio(a) como capaz de aprender. Também na dimensão processual, registou-se a emergência de um tipo de respostas não previstas, que reflectem o processo de aprendizagem como uma dinâmica de envolvimento afectivo (i.e. aprende-se através de um processo de motivação pessoal). Considerou-se este tipo de respostas como uma nova versão da sexta concepção (i.e. a aprendizagem como mudança pessoal), que se designou "motivando-se".

Na segunda análise (aplicação de um segundo sistema revisto de categorias, por dois juízes) todas as categorias foram detectadas por ambos os juízes. Por outro lado, o segundo juiz evocou a observação de dois tipos de respostas (do âmbito da dimensão processual) aparentemente não previstas. Tratava-se, em primeiro lugar, de respostas que descreviam o processo de aprendizagem como uma prática exploratória (ex.: "(...) aprende-se experimentando, fazendo, errando (...)"). Por discussão entre os juízes considerou-se que estas respostas podiam ser categorizadas na terceira concepção (i.e. memorização e aplicação), constituindo uma variante da noção de recuperação e utilização de conhecimentos adquiridos. Em segundo lugar, tratava-se de respostas que descreviam a dimensão processual da aprendizagem, fazendo referência à meta-aprendizagem (ex.: "aprender é essencialmente aprender $a$ aprender"). Igualmente por discussão entre juízes, considerou-se estas respostas como da quarta concepção (i.e. aprendizagem como compreensão), constituindo uma variante da noção de compreensão (uma compreensão que recai não na informação mas no próprio processo de aprendizagem).

Os resultados das duas análises permitiram chegar a um terceiro e último sistema de descrição das concepções de aprendizagem, que se apresenta de seguida (quadro 4, 5 e 6) e que é ilustrado com excertos de resposta.

Repare-se que é possível discriminar, por agrupamento das concepções de aprendizagem específicas identificadas, três concepções principais: 1) uma concepção "quantitativa" (categorias de R1 a R4 e de P1 a P3), que reflecte uma noção da aprendizagem como acumulação de conhecimento, por armazenamento; 2) uma concepção "qualitativa" (categorias R5 a R8 e P4, P6 e P7), que se refere à aprendizagem enquanto processo de compreensão, por transformação do conhecimento;3) uma concepção "intermédia" (categoria P5), que define a aprendizagem enquanto conjugação entre a memorização e a compreensão. 
Quadro 4 Sistema de descrição das concepções de aprendizagem - dimensão referencial (R) - "O que é aprender"

\begin{tabular}{|c|c|c|}
\hline Concepção & Definição & Resposta ilustrativa \\
\hline RO. Não articulada & $\begin{array}{l}\text { Ausência de uma definição articulada e } \\
\text { dirigida à questāo }\end{array}$ & $\begin{array}{l}\text { "Aprender é algo muito importante } \\
(\ldots) \text {." }\end{array}$ \\
\hline R1. Vaga & $\begin{array}{l}\text { Definição vaga - sinónimos de } \\
\text { "aprender", sem qualificação ou } \\
\text { elaboração - como se fosse evidente }\end{array}$ & $\begin{array}{l}\text { "Aprender refere-se ao processo } \\
\text { através do qual os indivíduos captam } \\
\text { as mais diversas formas de informação } \\
\text { que os rodeiam." }\end{array}$ \\
\hline R2. Aquisição de informação & $\begin{array}{l}\text { Aprender é aumentar os } \\
\text { conhecimentos pessoais }\end{array}$ & $\begin{array}{l}\text { "(aprender) Será quase como respirar, } \\
\text { uma vez que adquirimos } \\
\text { conhecimentos a toda a hora." }\end{array}$ \\
\hline $\begin{array}{l}\text { R3. Memorização e } \\
\text { reprodução }\end{array}$ & $\begin{array}{l}\text { Aprender é memorizar informação } \\
\text { (como em R2.) e ser capaz de a } \\
\text { reproduzir literalmente }\end{array}$ & $\begin{array}{l}\text { "Aprender e (...) tudo o que para mim } \\
\text { atinge um objectivo e a mensagem que } \\
\text { fol apreendida e que por sua vez vai } \\
\text { ser transmitida de volta a outras } \\
\text { pessoas." }\end{array}$ \\
\hline R4. Memorização e aplicação & $\begin{array}{l}\text { Aprender é memorizar informação } \\
\text { (como em R1. e R2.) e ser capaz de a } \\
\text { aplicar }\end{array}$ & $\begin{array}{l}\text { "(...) aprender significa captar } \\
\text { conhecimentos que, com os quais seja } \\
\text { possivel resolvermos determinados } \\
\text { problemas que se nos deparam." }\end{array}$ \\
\hline R5. Compreensão & $\begin{array}{l}\text { Aprender é compreender as coisas } \\
\text { (i.e. desenvolver uma concepção sobre } \\
\text { elas) }\end{array}$ & $\begin{array}{l}\text { "(...) aprender (...) é uma capacidade } \\
\text { que permite que cada homem } \\
\text { compreenda determinados fenómenos } \\
\text { e assuntos." }\end{array}$ \\
\hline R6. Compreensão e aplicação & $\begin{array}{l}\text { Aprender é compreender (como em } \\
\text { R5.) e ser capaz de aplicar o } \\
\text { conhecimento no mundo real }\end{array}$ & $\begin{array}{l}\text { "(...) o acto de aprender não se } \\
\text { restringe apenas à simples acção de } \\
\text { absorver informação, mas sim saber, } \\
\text { perceber e relacionar e utilizá-la } \\
\text { noutros contextos." }\end{array}$ \\
\hline \multirow[t]{2}{*}{$\begin{array}{l}\text { R7. Compreensão } \\
\text { interpretativa }\end{array}$} & $\begin{array}{l}\text { Versão a): aprender é compreender } \\
\text { (como em R5.) e mudar a concepção } \\
\text { que se tem das coisas (i.e. } \\
\text { reinterpretar o conhecimento) }\end{array}$ & $\begin{array}{l}\text { "Somos seres sensíveis, recebemos } \\
\text { muita informação do mejo exterior e, } \\
\text { aprender é a capacidade que temos de } \\
\text { receber, e sobretudo compreender, } \\
\text { reinterpretar essa informação em } \\
\text { função daquilo que são as nossas } \\
\text { vivências e conhecimentos prévios, } \\
\text { corrigindo então, se tal for o caso, ver } \\
\text { as coisas de outra forma (...)" }\end{array}$ \\
\hline & $\begin{array}{l}\text { Versão b): aprender é compreender } \\
\text { (como em R5.) e consciencializar as } \\
\text { diferentes perspectivas sobre as } \\
\text { coisas }\end{array}$ & $\begin{array}{l}\text { "(...) a aprendizagem (...) é sobretudo } \\
\text { conhecer novas situaçóes, novas vias } \\
\text { que nos levam a conhecer e entender } \\
\text { um pouco melhor tudo aquilo que nos } \\
\text { rodeia, aprendemos a ter diferentes } \\
\text { perspectivas de uma mesma } \\
\text { realidade." }\end{array}$ \\
\hline R8. Auto-actualização & $\begin{array}{l}\text { Aprender é mudar a concepção que se } \\
\text { tem das coisas (como em R5.) e } \\
\text { mudar assim como pessoa }\end{array}$ & $\begin{array}{l}\text { "Para mim, aprender é conseguir } \\
\text { conhecer e compreender determinada } \\
\text { questão ou fenómeno. Ao aprender sei } \\
\text { que 'cresço' enquanto pessoa (...)" }\end{array}$ \\
\hline
\end{tabular}


Quadro 5 Sistema de descrição das concepções de aprendizagem - dimensão processual (P) - "Como se aprende"

\begin{tabular}{|c|c|c|}
\hline Concepção & Definição & Resposta ilustrativa \\
\hline PO. Não articulada & $\begin{array}{l}\text { Ausência de uma resposta articulada } \theta \\
\text { dirigida à questão }\end{array}$ & "Aprende-se lendo." \\
\hline P1. Armazenando & $\begin{array}{l}\text { Aprende-se recolhendo e armazenando } \\
\text { a informação (l.e. acrescentando à que } \\
\text { já está armazenada) }\end{array}$ & $\begin{array}{l}\text { "A aprendizagem pode fazer-se por } \\
\text { memorização (...)" }\end{array}$ \\
\hline P2. Armazenando-decorando & $\begin{array}{l}\text { Aprende-se recolhendo e armazenando } \\
\text { informaçäo (como em P1.) mas } \\
\text { decorando }\end{array}$ & $\begin{array}{l}\text { "Pode aprender-se, estudando, } \\
\text { decorando }(. . .)^{\text {" }}\end{array}$ \\
\hline \multirow[t]{2}{*}{ P3. Aplicando } & $\begin{array}{l}\text { Versão a): aprende-se recuperando e } \\
\text { utilizando a informação armazenada }\end{array}$ & $\begin{array}{l}\text { "Aprender resulta da conjugação de } \\
\text { uma componente teórica, na qual se } \\
\text { adquiriu conhecimentos (...) com uma } \\
\text { componente prática, na qual se verifica } \\
\text { a aplicação desses conhecimentos na } \\
\text { realidade." }\end{array}$ \\
\hline & $\begin{array}{l}\text { Versão b): aprende-se modificando a } \\
\text { informação armazenada (de modo a } \\
\text { poder utilizá-la) } \\
\text { Versão c): aprende-se praticando de } \\
\text { forma exploratória }\end{array}$ & $\begin{array}{l}\text { "Esta aprendizagem é feita através de } \\
\text { um processo de acumulação, } \\
\text { organizaçäo e adaptação do s } \\
\text { conhecimentos a várias situações." } \\
\text { " (...) aprende-se experimentando, } \\
\text { fazendo, errando (...)" }\end{array}$ \\
\hline \multirow[t]{5}{*}{ P4. Compreendendo } & $\begin{array}{l}\text { Versão a): aprende-se analisando } \\
\text { criticamente a informação }\end{array}$ & $\begin{array}{l}\text { "Aprender é também querer questionar, } \\
\text { pôr em causa, investigar, ter a certeza } \\
\text { ou explicações aceitáveis para a } \\
\text { compreensão das coisas." }\end{array}$ \\
\hline & $\begin{array}{l}\text { Versão b): aprende-se } \\
\text { interrelacionando ideias ou } \\
\text { informações }\end{array}$ & $\begin{array}{l}\text { "O processo de aprendizagem dá-se } \\
\text { por (...) articulação entre } \\
\text { conhecimentos já adquiridos (...) o que } \\
\text { envolve um acto de pensar." }\end{array}$ \\
\hline & $\begin{array}{l}\text { Versão c): aprende-se desenvolvendo } \\
\text { uma perspectiva nova sobre um tópico }\end{array}$ & $\begin{array}{l}\text { "(...) para que se possa (aprender) (...) } \\
\text { temos de compreender em primeiro } \\
\text { lugar do que se trata, para depois } \\
\text { podermos debater o assunto com as } \\
\text { idejas e opiniōes próprias." }\end{array}$ \\
\hline & $\begin{array}{l}\text { Versão d): aprende-se } \\
\text { consciencializando as diferentes } \\
\text { perspectivas sobre um tópico }\end{array}$ & $\begin{array}{l}\text { "Aprende-se compreendendo aquilo } \\
\text { que se vê, ouve ou lê, apercebendo-se } \\
\text { de várias opiniōes para o mesmo } \\
\text { assunto, logo que se pode alterar, } \\
\text { melhorando a sua." }\end{array}$ \\
\hline & $\begin{array}{l}\text { Versão e): aprende-se por } \\
\text { compreensão do próprio processo de } \\
\text { aprendizagem }\end{array}$ & $\begin{array}{l}\text { "Aprender é essencialmente aprender a } \\
\text { aprender." }\end{array}$ \\
\hline P5. Conjugando & $\begin{array}{l}\text { Aprende-se conjugando a } \\
\text { memorização com a compreensão }\end{array}$ & $\begin{array}{l}\text { ("Para aprender (...) interligam-se a } \\
\text { memorização e a compreensäo.") }\end{array}$ \\
\hline P6. Generalizando & $\begin{array}{l}\text { Aprende-se generalizando do que se } \\
\text { aprende para outros domínios }\end{array}$ & $\begin{array}{l}\text { "(...) conseguir projectar (as matérias } \\
\text { estudadas) no quotidiano." }\end{array}$ \\
\hline
\end{tabular}




\begin{tabular}{l|l|l}
\hline P7. Modificando-se & $\begin{array}{l}\text { Versão a): aprende-se estabelecendo } \\
\text { uma relação recíproca com o que se } \\
\text { aprende (i.e. modificando-o e sendo } \\
\text { sujeito a uma mudança) }\end{array}$ & $\begin{array}{l}\text { "(...) processo interactivo em que } \\
\text { podemos pôr um pouco de nós no que } \\
\text { estamos a aprender." }\end{array}$ \\
\cline { 2 - 3 } $\begin{array}{l}\text { Versão b): aprende-se através de um } \\
\text { processo de motivação pessoal }\end{array}$ & $\begin{array}{l}\text { "Nem sempre se consegue aprender, } \\
\text { porque aprender significa algo que vai } \\
\text { ficar connosco, mas a verdade, mas a } \\
\text { verdade é que só se retém aquilo que } \\
\text { se gosta e que, pessoalmente nos } \\
\text { interessa. O resto, aquilo que temos } \\
\text { que saber, fica como que informações } \\
\text { soltas vagueando pelos arquivos } \\
\text { empoeirados do nosso cérebro." }\end{array}$ \\
\hline
\end{tabular}

Quadro 6 Sistema de descrição das concepções de aprendizagem — dimensão contextual (C) - "Onde se aprenden

\begin{tabular}{l|l|l}
\hline Concepção & Definição & Resposta ilustrativa \\
\hline Co. Não articulada & $\begin{array}{l}\text { Ausência de uma resposta articulada e } \\
\text { dirigida à questão }\end{array}$ & $\begin{array}{l}\text { "Aprende-se nos momentos de } \\
\text { aprendizagem." }\end{array}$ \\
\hline C1. Na escola & $\begin{array}{l}\text { A aprendizagem realiza-se nos contextos } \\
\text { académicos }\end{array}$ & $\begin{array}{l}\text { "Aprender é (...) adquirir ao longo do } \\
\text { percurso escolar (...) um conjunto de } \\
\text { competências (...)" }\end{array}$ \\
\hline C2. No mundo & $\begin{array}{l}\text { A aprendizagem realiza-se no contexto } \\
\text { alargado do ambiente (i.e. aprende-se em } \\
\text { qualquer lugar e em qualquer momento) }\end{array}$ & $\begin{array}{l}\text { "(...) aprendemos no dia a dia com a nossa } \\
\text { vivência (...)" }\end{array}$ \\
\hline
\end{tabular}

\section{Discussão}

Pela análise do sistema desenvolvido é possível constatar uma replicação, no contexto estudado, da maior parte das concepções de aprendizagem propostas pela perspectiva "fenomenográfica". No entanto, nem todas as concepções previstas teoricamente foram observadas e, em contrapartida, emergiram concepções novas.

No que diz respeito à dimensão referencial, confirmou-se a presença de todas as concepções previstas teoricamente (e respectivas versões), à excepção da concepção "institucional" (i.e. a aprendizagem como processo de obtenção de classificações) e da concepção "comunitária" (i.e. a aprendizagem enquanto obrigação social). Lembremos que a concepção "institucional" foi proposta apenas por Biggs (Biggs, 1989; 1990; Biggs \& Moore, 1993), não tendo também correspondente nos sistemas de Säljö (1979, cit. por Marton, 1988) ou de Marton, Dall'Alba e Beaty (1993). Talvez esta concepção seja mais facilmente detectada em estudantes pré-universitários. Quanto à concepção "comunitária", lembremos que esta concepção só foi encontrada, até agora, em estudantes orientais, talvez por estes(as) 
pertenceram a culturas menos individualistas que as culturas ocidentais, como a cultura portuguesa (veja-se, por exemplo, Hofstede, 1991).

Por outro lado, emergiu uma concepção não prevista (R6. Compreensão e aplicação), que implica uma representação da aprendizagem como um processo de compreensão do conhecimento associado à sua aplicação no mundo real. Esta concepção não consta dos sistemas propostos pela "fenomenografia", parecendo ser o correspondente qualitativo da concepção de aprendizagem como memorização e aplicação (categoria R4). ${ }^{10}$ Pode também ser vista como uma diferenciação da concepção de aprendizagem como compreensão (categoria R5), na medida em que acrescenta à noção de abstracção do significado dos fenómenos uma noção "prática", que salienta a necessidade de fazer uso desse conhecimento. Neste sentido, talvez R5 esteja reservada para indivíduos que valorizam mais o saber teórico e R6 para indivíduos que valorizam mais a aplicação prática, mas alicerçada na compreensão (i.e. uma representação da compreensão como meio de viabilizar a aplicação prática do conhecimento).

No que toca à dimensão processual, foram também confirmadas todas as concepções previstas. Para além disso, emergiram variantes não esperadas da concepção de aprendizagem por aplicação (i.e. P3. c: a noção de que a aprendizagem se processa por uma prática exploratória) e da concepção de aprendizagem por compreensão (i.e. P4. e: a noção de que a aprendizagem passa pelo aprender a aprender). A variante emergente P3. c talvez não seja mais que uma explicitação da versão P3. a, que defende que se aprende por utilização do saber adquirido (no caso P3. c essa "utilização" é "exploratória", da mesma forma que na versão P3. b ela passa por uma necessária "modificação" da informação). Noutra vertente, a variante emergente $\mathrm{P} 4$. e parece reflectir a consciência do processo metacognitivo como mecanismo de aprendizagem.

Por outro lado, para a concepção da aprendizagem por modificação pessoal (P7) não foi detectada nem a variante da aprendizagem por sucessivas mudanças pessoais, nem a variante da aprendizagem pela percepção de si próprio como capaz de aprender, ambas pertencentes ao sistema de Marton, Dall'Alba e Beaty (1993). Em contrapartida, emergiu uma variante nova de esta concepção, onde se entende que a aprendizagem se realiza através de um processo de motivação pessoal $(P 7.6 \mathrm{Mo}-$ tivando-se). Na realidade, esta variante parece traduzir a consciência da importância de uma motivação elevada ou intrínseca para uma aprendizagem eficaz (") $(a$ aquisição de conhecimentos faz-se) (...) através da curiosidade do indivíduo. "; "(..) só se retém aquilo que se gosta (...)) ou da importância da motivação para uma aprendizagem profunda ("(...) se eu aprender uma determinada matéria, mas sem interesse (...) não compreendo nada daquilo que me limitei a decorar, por isso não atingi a aprendizagem total. "), parecendo constituir, este último caso, uma consciência do fenómeno conceptualizado teoricamente como "abordagem da aprendizagem". ${ }^{11}$

10 Note-se, no entanto, que ela parece corroborar a possível associação entre a concepção qualitativa de aprendizagem e a noção da aprendizagem enquanto "aplicação de conhecimento", detectada por Cliff (1998). 
Ao nível da dimensão processual, emergiu igualmente uma concepção que defende a aprendizagem como resultado da conjugação entre a memorização e a compreensão da informação (P5: Conjugando). Esta concepção pode ser interpretada como uma evidência de replicação, neste contexto, da concepção "intermédia", detectada por outros estudos "fenomenográficos" mais recentes (Cliff, 1998; Marton \& Booth, 1997).

É também de salientar a confirmação das categorias previstas teoricamente da dimensão contextual, que traduzem uma noção de que a aprendizagem acontece quer ao nível do contexto académico, quer ao nível do contexto amplo da vivência pessoal.

Aidentificação de diferentes concepções de aprendizagem é relevante na medida em que sabemos que estas podem influenciar o processo e o resultado da aprendizagem. O aumento da qualidade da aprendizagem pode ser assim também conseguido pelo desenvolvimento da concepção de aprendizagem, que pode ser operado por intervenções adequadas para o efeito (ver Duarte, 2002).

\section{Referências}

Bakeman, R., \& Gottman, J. (1986). Observing interaction: An introduction to sequential analysis. Londres: Cambridge University Press.

Biggs, J. B. (1989). Approaches to the enhancement of tertiary teaching. Higher Education Research and Development, 8, 1, 7-25.

Biggs, J. B. (1990). Teaching for desired learning outcomes. In N. Entwistle (Ed.), Handbook of educational ideas and practices. Londres e Nova Iorque: Routledge.

Biggs, J. B., \& Moore P. J. (1993). The process of learning (3. ${ }^{\circ}$ ed.). Nova Iorque: Prentice Hall.

Boulton-Lewis, G. M., Wilss, L., \& Mutch, S. (1994). Teachers as adult learners: Their knowledge of their own learning and implications for teaching. Higher Education, 31, 93-106.

Brown, R. B. (1994). The language of learning and knowing: Bridging the apparent dichotomies. In G. Gibbs (Ed.), Improving student learning: Theory and practice. Oxford: The Oxford Centre for Staff Development.

Cliff, A. F. (1998). Teacher-learners' conceptions of learning: Evidence of a "communalist" conception amongst postgraduate learners? Higher Education, 35 (2), 205-220.

Dahlin, B., \& Regmi, M. P. (1997). Conceptions of learning among Nepalese students. Higher Education, 33 (4), 471-493.

Davies, A. (1995). Evaluating a deep approach to assessment. In G. Gibbs (Ed.), Improving student learning through assessment and evaluation. Oxford: The Oxford Centre for Staff Development.

11 O conceito de "abordagem da aprendizagem" refere-se ao modo como os/as estudantes se posicionam motivacional e estrategicamente face às tarefas de aprendizagem (ver Duarte, 2002). 
Duarte, A. (2000). Avaliação e modificação de concep̧̧̃es, motivações e estratégias de aprendizagem em estudantes do ensino superior. Dissertação de doutoramento não publicada, Faculdade de Psicologia e de Ciências da Educação da Universidade de Lisboa, Lisboa.

Duarte, A. M. (2002). Aprendizagem, ensino e aconselhamento educacional: Uma perspectiva cognitivo-motivacional. Porto: Porto Editora.

Eklund-Myrskog, G. (1998). Students' conceptions of learning in different educational contexts. Higher Education, 35, 299-316.

Entwistle, N. (Ed.) (1990). Handbook of educational ideas and practices. Londres e Nova Iorque: Routledge.

Flores, J. G. (1994). Análisis de datos cualitativos: Aplicaciones a la investigación educativa. Barcelona: PPV.

Garcia, M. G. (1996). Dar sentido a los datos: La combinación de perspectivas cualitativo y cuantitativo en el análisis de entrevistas (documento não publicado).

Gibbs, G. (1992). Improving the quality of student learning: Theory and practice. Bristol: TES.

Gibbs, G. (Ed.) (1995). Improving student learning through assessment and evaluation. Oxford: The Oxford Centre for Staff Development

Hofstede, G. (1991). Culture and organizations: Software of the mind. Nova Iorque: McGrawHill.

Hounsell, D. (1984). Learning and essay writing. In F. Marton, D. Hounsell, \& N. Entwistle (Eds.), The experience of learning. Edimburgo: The Scottish Academic Press.

Hounsell, D. (1988). Towards an anatomy of academic discourse: Meaning and context in the undergraduate essay. In R. Säljö (Ed.), The written world: Studies in literate thought and action. Berlim: Springer-Verlag.

Lamon, M., Chan, C., Scardamalia, M., Burtis, P. J., \& Brett, C. (1993). Beliefs about learning and constructive processes in reading: Effects of a computer supported intentional learning environment (CSILE). Comunicação apresentada no "Annual meeting of the American Educational Research Association", Atlanta, EUA.

Martin, E., \& Ramsden, P. (1987). Learning skill or skill in learning? In J. T. Richardson, M. W. Eysenck, \& D. W. Piper (Eds.), Student learning: Research in education and cognitive psychology. Milton Keynes: SRHE \& Open University Press.

Marton, F. (1988). Describing and improving learning. In R. Schmeck (Ed.), Learning strategies and learning styles. Nova Iorque: Plenum.

Marton, F., \& Booth, S. (1997). Learning and awareness. Mahwah: Lawrence Erlbaum.

Marton, F., Dall'Alba, G., \& Beaty, E. (1993). Conceptions of learning. International Journal of Educational Research, 19 (3), 277-300.

Marton, F., Hounsell, D., \& Entwistle, N., (Eds.) (1984). The experience of learning. Edimburgo: Scottish Academic Press.

Miles, M. B., \& Huberman, A. M. (1994). Qualitative data analysis: An expanded sourcebook (2." ed.). Thousand Oaks, CA: Sage Publications.

Perry, W. G. (1970). Forms of intellectual and ethical development in the college years: A scheme. Nova Iorque: Holt, Rinehart and Winston.

Richardson, J. T., Eysenck, M. W., \& Piper, D. W. (Eds.) (1987). Student learning: Research in education and cognitive psychology. Milton Keynes: SRHE \& Open University Press. 
Rosário, P. S. (1999). Variáveis cognitivo-motivacionais na aprendizagem: As "abordagens ao estudo" em alunos do Ensino Secundário. Dissertação de doutoramento não publicada, Instituto de Educação e Psicologia - Universidade do Minho, Braga.

Ryan, M. P. (1984). Monitoring text comprehension: Individual differences in epistemological standards. Journal of Educational Psychology, 76, 2, 248-58.

Säljö, R. (1979). Learning about learning. Higher Education, 8, 443-451.

Säljö, R. (1984). Learning from reading. In F. Marton, D. Hounsell, \& N. Entwistle (Eds.), The experience of learning. Edimburgo: The Scottish Academic Press.

Säljö, R. (Ed.) (1988). The written world: Studies in literate thought and action. Berlin: Springer-Verlag.

Schmeck, R. (Ed.) (1988). Learning strategies and learning styles. Nova Iorque: Plenum.

Van den Brink, K., Alemany, I., Plat, A., Duarte, A., Ericsson, L., \& Slack, R. (2000). Students' learning with educational multimedia in school: A multinational study. Comunicação apresentada no $X$ Colóquio AFIRSE Portuguesa, Faculdade de Psicologia e de Ciências da Educação/Universidade de Lisboa, Lisboa.

Van Rossum, E. J., \& Schenk, S. (1984). The relationship between learning conception, learning strategy and learning outcome. British Journal of Educational Psychology, 54, 73-83.

Learning conceptions of Portuguese university students (abstract). This study aimed to characterise learning conceptions of Portuguese university students. A sample of students answered to an open question on meaning, process and learning context. Answers were subjected to content analysis. Results replicate most learning conceptions founded, in other contexts, by "phenomenographical" research (i.e. the distinction is between learning as memorisation and as comprehension). There was also the occurrence of a less represented conception, which defines learning as a conjugation of memory and comprehension. Furthermore, other variants of already detected learning conceptions emerged (i.e. "one learns by": exploratory practice; comprehension of the learning process; motivation) as well as what it seems a new conception (i.e. learning as knowledge comprehension and application).

António M. Duarte, António Duarte, Faculdade de Psicologia e de Ciências da Educação/ Universidade de Lisboa (antonio.duarte@fpce.ul.pt) 